\title{
Meta-analysis of pharmacogenetic interactions in amyotrophic lateral sclerosis clinical trials OPEN
}

Ruben P.A. van Eijk, MD Ashley R. Jones, PhD William Sproviero, PhD Aleksey Shatunov, PhD Pamela J. Shaw, MD, PhD P. Nigel Leigh, MD, PhD Carolyn A. Young, MD, $\mathrm{PhD}$

Christopher E. Shaw, $\mathrm{MD}, \mathrm{PhD}$

Gabriele Mora, MD Jessica Mandrioli, MD Giuseppe Borghero, MD Paolo Volanti, MD

Frank P. Diekstra, MD, $\mathrm{PhD}$

Wouter van Rheenen, MD, PhD

Esther Verstraete, MD, $\mathrm{PhD}$

Marinus J.C. Eijkemans, $\mathrm{PhD}$

Jan H. Veldink, MD, PhD Adriano Chio, MD, PhD*

Ammar Al-Chalabi, PhD, FRCP*

Leonard H. van den Berg, $\mathrm{MD}, \mathrm{PhD}^{*}$

Michael A. van Es, MD, $\mathrm{PhD}^{*}$

For UKMND-LiCALS and LITALS Study Group

Correspondence to

Dr. van Es:

m.a.vanes@umcutrecht.nl

or Dr. Al-Chalabi:

ammar.al-chalabi@kcl.ac.uk

\section{Editorial, page 1850}

Supplemental data at Neurology.org

\section{ABSTRACT}

Objective: To assess whether genetic subgroups in recent amyotrophic lateral sclerosis (ALS) trials responded to treatment with lithium carbonate, but that the treatment effect was lost in a large cohort of nonresponders.

Methods: Individual participant data were obtained from 3 randomized trials investigating the efficacy of lithium carbonate. We matched clinical data with data regarding the UNC13A and C9orf72 genotype. Our primary outcome was survival at 12 months. On an exploratory basis, we assessed whether the effect of lithium depended on the genotype.

Results: Clinical data were available for 518 of the 606 participants. Overall, treatment with lithium carbonate did not improve 12-month survival (hazard ratio [HR] 1.0, 95\% confidence interval [CI] 0.7-1.4; $p=0.96)$. Both the UNC13A and C9orf72 genotype were independent predictors of survival ( $\mathrm{HR} 2.4,95 \% \mathrm{Cl} 1.3-4.3 ; p=0.006$ and $\mathrm{HR} 2.5,95 \% \mathrm{Cl} 1.1-5.2 ; p=0.032$, respectively). The effect of lithium was different for UNC13A carriers ( $p=0.027$ ), but not for C9orf72 carriers ( $p=0.22)$. The 12-month survival probability for UNC13A carriers treated with lithium carbonate improved from 40.1\% (95\% Cl 23.2-69.1) to 69.7\% (95\% Cl 50.4-96.3).

Conclusions: This study incorporated genetic data into past ALS trials to determine treatment effects in a genetic post hoc analysis. Our results suggest that we should reorient our strategies toward finding treatments for ALS, start focusing on genotype-targeted treatments, and standardize genotyping in order to optimize randomization and analysis for future clinical trials. Neurology ${ }^{\circledR}$ 2017;89:1915-1922

\section{GLOSSARY}

ALS = amyotrophic lateral sclerosis; ALSFRS-R = Amyotrophic Lateral Sclerosis Functional Rating Scale-revised; $\mathbf{C l}=$ confidence interval; GWAS = genome-wide association studies; HR = hazard ratio; IPD = individual participant data; $\mathbf{S N P}=$ single nucleotide polymorphism.

Despite considerable efforts, riluzole is still the only drug that has been shown to increase survival in patients with amyotrophic lateral sclerosis (ALS). ${ }^{1}$ Phenotypic, genetic, and pathophysiologic heterogeneity form a plausible explanation for the large number of negative trials in ALS. ${ }^{2}$ Although the mechanisms underlying ALS are not fully understood, ${ }^{2}$ it is clear that genetic variation plays an important role in both familial and sporadic ALS. ${ }^{3}$ It is reasonable to hypothesize that mutations in many different genes may act through several different pathways, but that they all cause motor neurodegeneration and manifest with an ALS phenotype. It

\footnotetext{
*These principal investigators contributed equally to this work.

From the Department of Neurology, Brain Centre Rudolf Magnus (R.P.A.v.E., F.P.D., W.v.R., J.H.V., L.H.v.d.B., M.A.v.E.), and Department of Biostatistics and Research Support (M.J.C.E.), University Medical Centre Utrecht, the Netherlands; Maurice Wohl Clinical Neuroscience Institute and United Kingdom Dementia Research Institute Centre (A.R.J., W.S., A.S., C.E.S., A.A.-C.), Department of Basic and Clinical Neuroscience, King's College London; Sheffield Institute for Translational Neuroscience (SITraN) (P.J.S.), University of Sheffield, South Yorkshire; Department of Clinical Neuroscience (P.N.L.), Trafford Centre for Biomedical Research, Brighton and Sussex Medical School, Falmer, Brighton; The Walton Centre NHS Trust (C.A.Y.), Liverpool, UK; Istituti Clinici Scientifici Maugeri IRCSS (G.M.), Milan; Department of Neuroscience (J.M.), Sant'Agostino-Estense Hospital and University of Modena and Reggio Emilia, Modena; Department of Neurology (G.B.), Azienda Universitario Ospedaliera di Cagliari and University of Cagliari; Istituti Clinici Scientifici Maugeri IRCSS (P.V.), Mistretta, Italy; Rijnstate Ziekenhuis (E.V.), Arnhem, the Netherlands; Rita Levi Montalcini’ Department of Neuroscience (A.C.), ALS Centre, University of Torino; and Azienda Ospedaliera Città della Salute e della Scienza (A.C.), Turin, Italy.

Members of the UKMND-LiCALS and LITALS Study Group are listed at Neurology.org.

Go to Neurology.org for full disclosures. Funding information and disclosures deemed relevant by the authors, if any, are provided at the end of the article. The Article Processing Charge was funded by Research Councils UK.

This is an open access article distributed under the terms of the Creative Commons Attribution License 4.0 (CC BY), which permits unrestricted use, distribution, and reproduction in any medium, provided the original work is properly cited.
} 
may, therefore, be conceivable that different subtypes of ALS respond differently to disease-modifying therapies and multiple individually tailored therapies may need to be developed to treat the disease effectively.

Within the field of oncology, the treatment for a specific type of malignancy often depends on the genetic tumor characteristics. For instance, patients with melanoma and $B R A F$ gene mutations have significantly improved rates of overall and progression-free survival when treated with a BRAF kinase inhibitor. ${ }^{4}$ It seems that therapeutic strategies for ALS are also moving toward precision medicine and groundbreaking targeted trials for SOD1-related ALS have already been undertaken or are underway with antisense oligonucleotides, ${ }^{5}$ arimoclomol (ClinicalTrials.gov NCT00706147), and pyrimethamine. $^{6}$

In this study, we explore the possibility that patients with genetic subgroups of ALS may have responded to treatment in previously conducted negative trials evaluating lithium carbonate, but that a proportionally larger cohort of nonresponders diluted the treatment effect in the overall analysis.

METHODS Study design. When performing post hoc analyses according to genotype and re-estimating treatment effects for genetic subgroups, it is important to recognize that several problems will arise. First, the sample size within each subgroup will decrease dramatically and statistical power to detect treatment differences is severely reduced. Second, obtaining DNA samples and genetic screening is not standard practice in ALS clinical trials, thus one can expect that genetic data will be missing. Finally, over 30 genes have been associated with ALS. This may further reduce the statistical power by multiple testing, but more importantly, will inflate the false-positive risk. To overcome these issues, we performed an individual participant data (IPD) meta-analysis of randomized controlled trials with lithium carbonate in ALS; multiple trials with this compound have been performed and, therefore, a large sample size could be obtained. Moreover, an IPD meta-analysis enabled us to reduce the false-positive risk by validating trends in independent cohorts of patients and improve generalizability. Genetic post hoc analyses were limited to (1) genes in which variation is relatively common in order to ensure sufficient numbers and (2) genes known to be modifiers of prognosis. We therefore included 2 genetic subgroups: (1) C9orf72 repeat expansion carriers and (2) patients homozygous for the $\mathrm{C}$ allele of rs12608932 located in UNC13A. Repeat expansions in C9orf72 are the most common genetic cause of ALS and are found in approximately 5\%-10\% of patients with ALS of European descent (familial and sporadic cases combined) ${ }^{7.8}$ Genome-wide association studies (GWAS) have repeatedly detected an association for a single nucleotide polymorphism (SNP: rs12608932) located in the UNC13A gene..$^{9-11}$ The effect of this SNP on disease risk is modest, with an odds ratio $<1.30$, but appears to convey a large effect on survival. Multiple studies have shown that the mean survival in patients homozygous for the $\mathrm{C}$ allele of rs12608932 is 6 to 12 months shorter, implying that this SNP, or variants in linkage disequilibrium with it, is a strong phenotypic modifier and therefore of biological relevance. ${ }^{12-15}$ Approximately $16 \%$ of patients with ALS are homozygous for the C allele of rs12608932. ${ }^{9-11}$

Search strategy and study selection. To identify randomized clinical trials evaluating the efficacy of lithium carbonate in patients with ALS, we systematically searched the PubMed database, Embase, Cochrane Library, Web of Science, and online clinical trial registers (ClinicalTrials.gov, EudraCT, and IRCTN) up to November 2016. The following search terms were used: "amyotrophic lateral sclerosis" or "motor neuron* disease" or "Lou Gehrig*," and "lithium*." Reference lists from relevant reviews and included trials were screened in order to retrieve additional studies. Only clinical trials published in English were included. Each study was assessed for its methodologic quality and risk of bias for confounding, detection, performance, attrition, and reporting bias. ${ }^{16}$ We included only randomized clinical trials with an overall low risk of bias; see table e-1 at Neurology. org for the scoring of the included studies. We identified 4 clinical trials that provided a minor risk of bias and subsequently contacted the relevant corresponding authors for the individual participant and genotypic data (figure e-1). Three groups (the Netherlands, United Kingdom, and Italy) agreed to participate in the IPD meta-analysis with genetic post hoc analyses.

Standard protocol approvals, registrations, and patient consents. The initial trials were all conducted according to the International Conference on Harmonisation Good Clinical Practice guidelines and with the approval of local ethical and institutional review boards. All informed consents permitted the use of IPD for future post hoc analyses, but did not specifically state genetic post hoc analyses. We therefore obtained permission from local ethical and institutional review boards to use existing genotype data from genetic studies in which trial participants were simultaneously enrolled, or to genotype DNA samples if available. This meant that the trials and genetic studies had to be temporarily deanonymized in order to match clinical data to genetic data or DNA samples. After linking these files, the data were reanonymized.

Genotyping of DNA samples. For all samples, C9orf72 had either been genotyped previously or was genotyped after obtaining a DNA sample using repeat-primed PCR as described previously. ${ }^{17}$ The majority (64\%) of the available DNA samples from trial participants has been included in previously conducted GWAS using Illumina (San Diego, CA) BeadChips and provided genotype data for rs 12608932 . In the remaining samples (36\%), this SNP was genotyped using Taqman (Applied Biosystems, Foster City, CA) assays, as described previously. ${ }^{18}$

Definitions and outcome measures. Based on previous literature, patients with the $U N C 13 A \mathrm{C} / \mathrm{C}$ genotype were classified as $U N C 13 A$ carriers in the subsequent analyses; the remaining patients with the $U N C 13 \mathrm{~A} \mathrm{~A} / \mathrm{C}$ or $\mathrm{A} / \mathrm{A}$ genotype were classified as noncarriers. ${ }^{14}$ Patients with more than 30 repeats in the C9orf 72 gene were considered to be $C 90 r f 72$ carriers. ${ }^{19}$ Our a priori primary measure of treatment efficacy was death from any cause at 12 months after randomization. Due to the high adverse event and nonadherence rate, setting the follow-up to 12 months was thought to best capture a possible therapeutic effect and minimize the risk of diluting the effect by the intention-to-treat principle of analysis.

Statistical analysis. All outcomes were analyzed according to the intention-to-treat principle of analysis. We chose to analyze the IPD from the 3 trials using a one-step meta-analytic approach. 


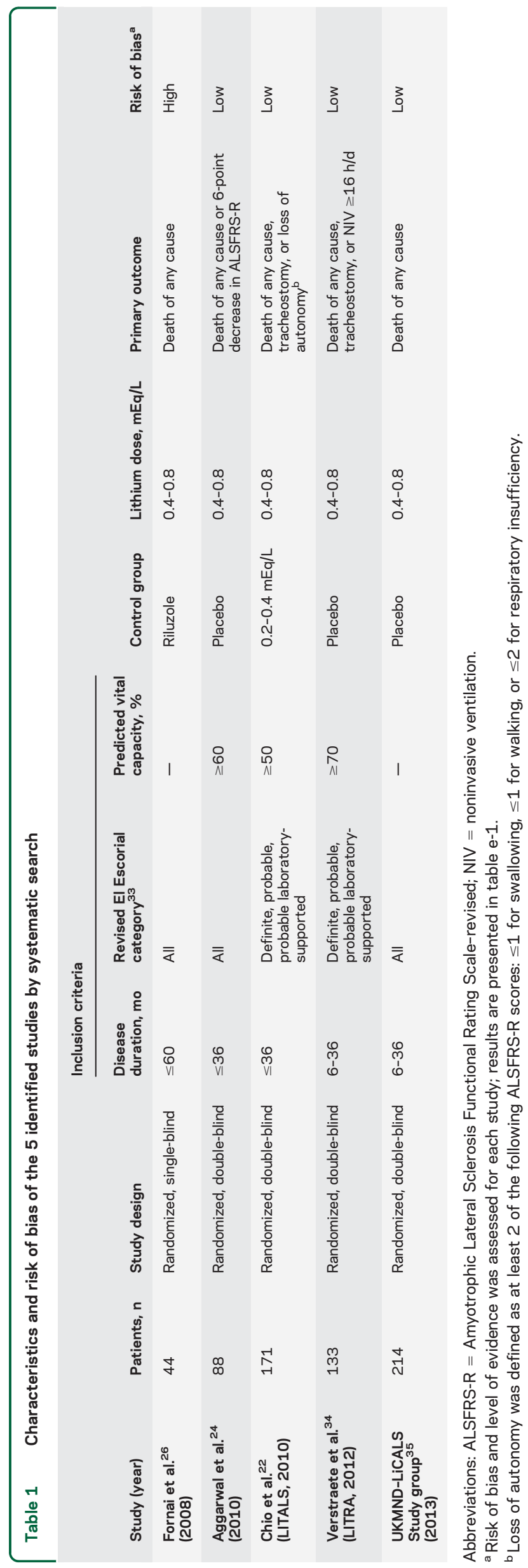

Previous studies have shown that a one-step meta-analytic approach provides similar treatment effect estimates, if clustering is appropriately accounted for, in comparison with a 2-step approach (e.g., first summarizing the individual trial data [step 1], before pooling the effect estimates [step 2]). ${ }^{20}$ The IPD from the 3 studies were merged together and a study indicator variable was created. We performed a pooled analysis, while adjusting for the clustering within studies by stratifying each analysis for the study indicator. Missing data in covariates $(1.5 \%$ of the cases had at least one missing value) did not predict the outcome $(p=$ 0.50 ); therefore, all missing values in the covariates, except for the genetic data, were imputed with their mean. Unlike in observational studies, mean imputation has been shown to give unbiased estimates of the treatment effect in randomized controlled trials. ${ }^{21}$ When we analyzed genetic interactions with lithium carbonate, we used only patients with complete genetic data, as phenotypic variables were unable to predict the genotype accurately. We prespecified one sensitivity analysis by estimating the treatment effect with and without the control group of Chio et al., ${ }^{22}$ as this control group used a subtherapeutic dose of lithium (0.2-0.4 $\mathrm{mEq} / \mathrm{L}$ instead of $0.4-0.8 \mathrm{mEq} / \mathrm{L}$ ).

The time to event outcome was analyzed using Cox proportional hazard models, stratified by the study indicator. Adjustment for prognostic covariates substantially increases the statistical power of Cox proportional hazard models. ${ }^{23}$ Therefore, we selected the most important predictors by stepwise backward selection using Akaike Information Criterion. The selected predictors were subsequently added to the model. Next, the treatment indicator variable (lithium or control) was incorporated in the model. The difference in log likelihoods between a model with and without the treatment variable was calculated and significance testing was done by the likelihood ratio test. Using the same testing procedure, we evaluated whether the treatment effect depended on the C9orf72 or UNC13A genotype by incorporating 2 -way interaction terms. Due to the exploratory, nonconfirmatory nature of this genetic post hoc subgroup analysis, we did not correct significance levels for multiple testing. Results were considered significant when the 2 -sided $p$ value was lower than 0.05 .

RESULTS Data were available for 518 participants in 3 randomized clinical trials evaluating the efficacy of lithium carbonate; study characteristics are given in table 1. Individual data were not available from 1 of the 4 clinical trials (study by Aggarwal et al. ${ }^{24}$ ), which involved 88 participants. Baseline characteristics of the participants included in the analysis are given in table 2. Complete data regarding the main prognostic confounders were available for $98.5 \%$ of the participants (8 patients had an unknown date of onset). In total, $261(50.4 \%)$ patients received lithium carbonate and 257 (49.6\%) patients were allocated to the control arm, in which 174 patients received placebo (67.4\%) and 83 patients a subtherapeutic dose of lithium carbonate $(32.3 \%)$. The baseline characteristics were well-balanced between the lithium carbonate and control groups.

Age, Amyotrophic Lateral Sclerosis Functional Rating Scale-revised (ALSFRS-R) slope, and vital capacity at baseline were predictors for survival at 12 months (all $p<0.001$ ) and were adjusted for in all 
Table 2 Clinical characteristics of patients included in pooled analysis

\begin{tabular}{|c|c|c|c|c|c|c|}
\hline & LITALS $(n=171)$ & LiCALS $(n=214)$ & LITRA $(n=133)$ & Total $(n=518)$ & Lithium $(n=261)$ & Control $(n=257)$ \\
\hline Age at randomization, $y$ & $58(11)$ & 60 (11) & $58(12)$ & 59 (11) & $58(12)$ & $59(11)$ \\
\hline Female & $71(42)$ & 66 (31) & $53(40)$ & 190 (37) & 96 (37) & 94 (37) \\
\hline Disease duration at randomization, mo & $19(10)$ & $19(8)$ & $15(8)$ & $18(9)$ & $18(9)$ & $18(9)$ \\
\hline Bulbar site of onset & $41(24)$ & $47(22)$ & $38(29)$ & $126(24)$ & $62(24)$ & $64(25)$ \\
\hline Predicted upright vital capacity & $85(21)$ & $91(18)$ & $95(17)$ & $90(19)$ & $90(19)$ & $90(19)$ \\
\hline ALSFRS-R & $37(6)$ & 38 (6) & $40(5)$ & $38(6)$ & $39(6)$ & 38 (6) \\
\hline
\end{tabular}

Abbreviations: ALSFRS-R = Amyotrophic Lateral Sclerosis Functional Rating Scale-revised. Data are mean (SD) or $\mathrm{n}(\%)$.

subsequent analyses (table e-2). Overall, 75.3\% (95\% confidence interval [CI] 69.9-81.2) of the patients in the control arm and $74.7 \%$ (95\% CI 69.1-80.6) in the lithium arm were still alive at 12 months, corresponding to an adjusted hazard ratio (HR) of 1.0 (95\% CI 0.7-1.4; $p=0.96$; figure 1A). Excluding the subtherapeutic control group from the analysis did not change the treatment effect (HR 1.3, 95\% CI $0.9-2.1 ; p=0.21$. Next, we evaluated the prespecified genetic subgroup interactions in all patients with genetic data $(\mathrm{n}=269)$; the baseline characteristics are given in tables 3 and e-3. Both the UNC13A and $C 9$ orf 72 genotype were independent predictors for 12-month survival, with an adjusted HR of 2.4 (95\% CI $1.3-4.3 ; p=0.006)$ and HR $2.5(95 \%$ CI $1.1-5.2 ; p=0.032$ ), respectively (figure $1 \mathrm{~B}$ ). The overall effect of lithium carbonate in the patients with genetic data remained futile (HR 0.8, 95\% CI 0.4$1.4 ; p=0.39$ ).

The treatment effect was different for the UNC13A carriers ( $\mathrm{n}=46 ; p=0.027)$ but not for the C9orf72 carriers ( $\mathrm{n}=25 ; p=0.22$ ). Lithium carbonate in UNC13A carriers resulted in a $70 \%$ reduction in the number who died during the 12 month follow-up period as compared to the placebo group (HR 0.3, 95\% CI 0.1-0.9), whereas the noncarriers did not benefit from lithium carbonate (HR 1.2, 95\% CI 0.6-2.3; figure 2). The significant treatment interaction with $U N C 13 A$ genotype remained after correcting for the interaction between the C9orf72 genotype and lithium ( $p=0.020$ ) or excluding the control group from the LITALS study ( $p=$ 0.047). The interaction between lithium treatment and $U N C 13 A$ was homogenous across the 3 different studies (3-way interaction Cox model; $p=0.99$; figure e-2). Baseline characteristics of the UNC13A carriers are given in table e-3 $(n=46)$. The crude Kaplan-Meier estimate of 12-month survival probability for UNC13A carriers improved from 40.1\% (95\% CI 23.2-69.1) in the control group $(\mathrm{n}=26)$ to $69.7 \%$ (95\% CI 50.4-96.3) in the lithium group $(\mathrm{n}=20)(p=0.056)$. When we adjusted for baseline inequalities (vital capacity and sex), lithium treatment was effective $(p=0.039)$, and remained so when we additionally corrected for age and ALSFRS-R slope $(p=0.040)$

DISCUSSION In this study, we have shown the importance of including genetic information in clinical trials for ALS. Our results reveal that even within a well-defined and selected trial population, considerable differences in the primary outcome can be expected for patients with either the UNC13A C/C genotype or C9orf72 repeat expansion. Interestingly, we showed that the overall meta-analysis of trials with lithium carbonate in ALS is futile, but that a genetic subgroup of patients (UNC13A C/C genotype) may benefit from this treatment. Due to the small sample size of this genetic subgroup (fewer than $20 \%$ of the cases), the signal indicating response may have been lost within the large group of nonresponders.

Although our genetic knowledge about causative and disease-modifying genes in ALS is growing exponentially, ${ }^{3}$ we have not yet managed to translate these novel findings into effective therapeutic strategies. To date, only 2 targeted (phase I) genetic trials have been completed and a number of targeted trials are currently underway. ${ }^{5,6}$ By showing that genetic variation in ALS genes significantly influences the primary outcome measure of a clinical trial and may alter treatment response, we have demonstrated the importance of incorporating genetic data in the analysis of ALS trials. Unequally balanced genotypes across treatment and control groups, especially in smaller studies, may greatly influence the false-positive and false-negative rates and the validity of clinical trials in ALS as a whole. For instance, the probability of an imbalance larger than $10 \%$ between treatment arms, if the prognostic factor is present in $15 \%$ of the cases (like $U N$ $C 13 A$ C/C genotype), is 0.24 and 0.10 for trial sizes of $n=50$ and $n=100$, respectively. ${ }^{25}$ It might therefore even be conceivable that the high falsepositive rate of the phase II trial in ALS ${ }^{2}$ is partially caused by an imbalance of disease-modifying genetic 
A

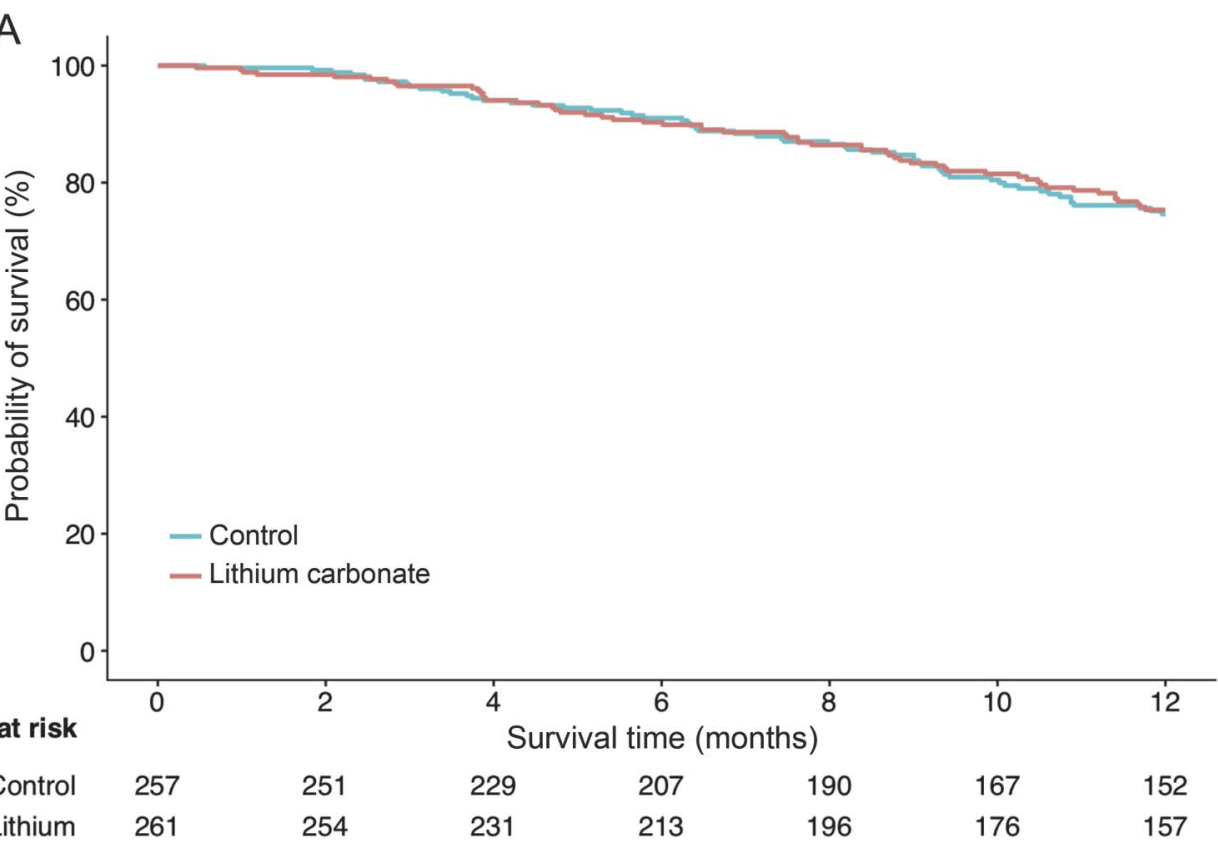

Number at risk

Contro

261

254

231

213

196

157

B

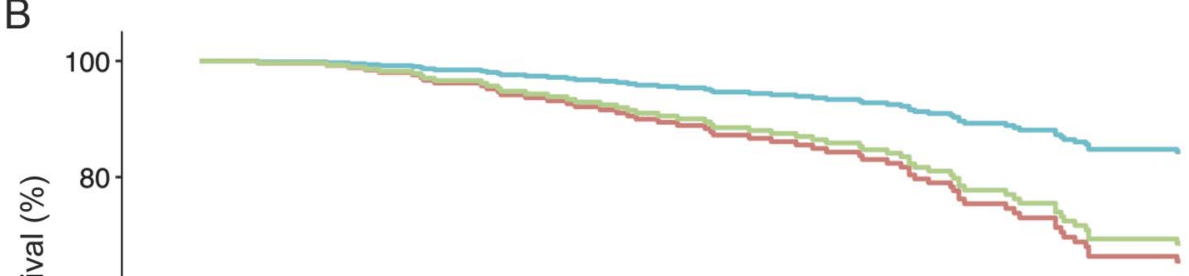

20- - Noncarriers

- C9orf72 carriers

- UNC13A carriers

0

0

Number at risk

Noncarriers

C9orf72 carriers

UNC13A carriers

201

22

46

2

198

20

45

\begin{tabular}{ccccc}
4 & 6 & 8 & 10 & 12 \\
\multicolumn{2}{c}{ Survival time } & (months) & & \\
182 & 164 & 150 & 133 & 128 \\
17 & 16 & 15 & 11 & 6 \\
39 & 31 & 27 & 22 & 17
\end{tabular}

Survival time (months)

Pooled 12-month survival in 3 clinical trials evaluating the efficacy of lithium carbonate. (A) Overall treatment effect of lithium carbonate was nonsignificant (hazard ratio [HR] 1.0, 95\% confidence interval [Cl] 0.7-1.4). (B) There was a significant effect of genetic subgroups on 12-month survival, irrespective of treatment arm, within the clinical trials (UNC13A HR 2.4, $95 \% \mathrm{Cl} 1.3-4.3 ; p=0.006$; and C9orf72 HR 2.5, 95\% Cl 1.1-5.2; $p=0.032$ ). Three patients had both risk variants of UNC13A and C9orf72; the number at risk of these patients is merged with the UNC13A carriers.

variants between treatment arms in these studies. The false-positive risk may be further inflated by the limited sample size often used for phase II ALS trials.

Lithium for ALS first came into the spotlight after an initial report that suggested an important improvement of survival following lithium treatment. ${ }^{26}$ Our study, combining the results of 3 randomized placebo-controlled trials, excludes an overall treatment effect similar to riluzole. We had $89 \%$ power to detect a $10 \%$ absolute increase in survival. ${ }^{27} \mathrm{We}$ found, however, that the treatment effect of lithium carbonate was not homogenous across patients. The 
Table 3 Comparison of the baseline characteristics between patients with and without genetic data

\begin{tabular}{|c|c|c|c|c|}
\hline & \multirow[b]{2}{*}{$\begin{array}{l}\text { Patients without genetic } \\
\text { data }(\mathrm{n}=249)\end{array}$} & \multicolumn{3}{|c|}{ Patients with genetic data } \\
\hline & & Total $(n=269)$ & Lithium $(n=129)$ & Control $(n=140)$ \\
\hline Age at randomization, y & $60(11)$ & $58(11)$ & $57(11)$ & $59(11)$ \\
\hline Women & $83(33)$ & $107(40)$ & $54(42)$ & $53(38)$ \\
\hline Disease duration at randomization, mo & $17(8)$ & $18(9)$ & $18(9)$ & $19(9)$ \\
\hline Bulbar site of onset & $66(27)$ & $60(22)$ & $27(21)$ & $33(24)$ \\
\hline Predicted upright vital capacity & $88(19)$ & $92(19)$ & $92(19)$ & $91(19)$ \\
\hline ALSFRS-R & $38(6)$ & $39(6)$ & $39(6)$ & $39(6)$ \\
\hline C9orf72 expansion carriers & $249(48)^{a}$ & $25(9)$ & $14(11)$ & $11(8)$ \\
\hline LiCALS & $157(73)^{\mathrm{a}}$ & $6(11)$ & $2(7)$ & $4(13)$ \\
\hline LITALS & $73(57)^{a}$ & $8(8)$ & $5(10)$ & $3(6)$ \\
\hline LITRA & $19(14)^{a}$ & $11(10)$ & $7(13)$ & $4(7)$ \\
\hline UNC13A C/C genotype carriers & $249(48)^{a}$ & $46(17)$ & $20(16)$ & $26(19)$ \\
\hline LiCALS & $157(73)^{\mathrm{a}}$ & $11(19)$ & 6 (22) & $5(17)$ \\
\hline LITALS & $73(57)^{a}$ & $18(18)$ & 9 (19) & $9(18)$ \\
\hline LITRA & $19(14)^{a}$ & $17(15)$ & 5 (9) & $12(20)$ \\
\hline
\end{tabular}

Abbreviations: ALSFRS-R = Amyotrophic Lateral Sclerosis Functional Rating Scale-revised.

Data are mean (SD) or $\mathrm{n}(\%)$. Three patients had both risk variants of UNC13A and C9orf72.

${ }^{a}$ Number (\%) missing.

observation that patients with ALS homozygous for the C allele of rs12608932 in UNC13A may benefit from lithium may warrant further research. The
UNC13A protein is involved in synaptic vesicle maturation and neuronal outgrowth. ${ }^{28}$ Lithium has been shown to influence many pathways, including the

Figure 2 Cox proportional hazards model of 12-month survival and the interaction of lithium carbonate with UNC13A genotype

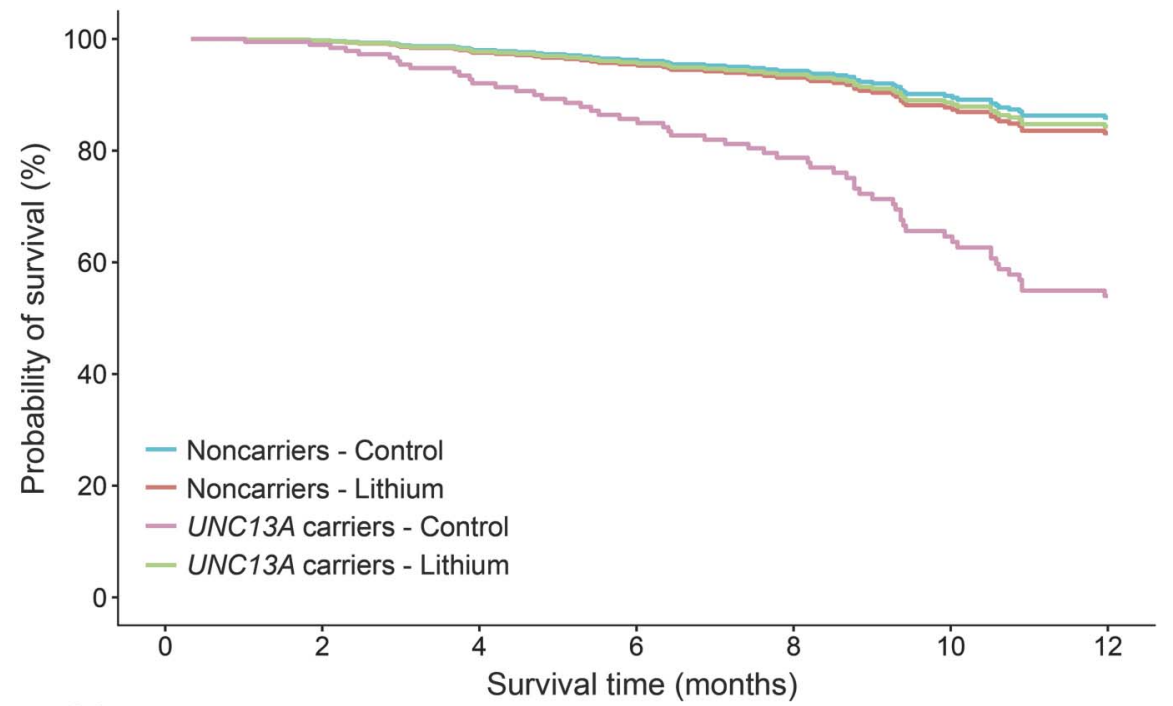

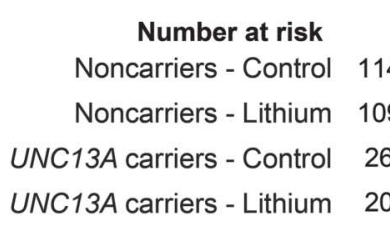

114

112

106

25

20

105
94
20
19

96
84
15
16

89
76
13
14

$\begin{array}{cc}76 & 69 \\ 68 & 65 \\ 10 & 7 \\ 12 & 10\end{array}$

Incorporating interaction terms between treatment arm (control or active) and UNC13A carrier status revealed that the effect of lithium carbonate significantly depended on the UNC13A carrier status ( $p=0.027)$. Lithium carbonate improved the 12-month survival in individuals with the UNC13A C/C genotype, but had no effect in noncarriers. 
induction of sprouting of pyramidal neurons in the corticospinal tract and the promotion of synaptogenesis, and plays a role in autophagy. ${ }^{29}$ All these mechanisms are potentially relevant to ALS. However, it has also been shown that rs 12608932 influences the expression of the nearby KCNN1 gene, ${ }^{30,31}$ which encodes a potassium calcium-activated channel. It is therefore also possible that lithium influences KCCN1 or acts through other pathways.

Without a solid understanding of the biological interaction between the treatment and pathophysiologic pathway, it is challenging to robustly identify the responder group, without increasing the risk of drawing false-positive or false-negative conclusions. ${ }^{32}$ We reduced this likelihood by only testing 2 prespecified pharmacogenetic interactions and selecting genotypes that are relatively commonly occurring in the general ALS population. Moreover, by using data from 3 independent cohorts, we could assess whether the signal is consistent across studies. Nevertheless, the evidence we provide regarding the interaction between UNC13A and lithium carbonate is still exploratory and hypothesis-generating. This finding does, however, warrant further exploration of lithium carbonate in a well-balanced, blinded, randomized clinical trial specifically targeted at patients with ALS and the UNC13A C/C genotype. Such a trial, and future genetic trials for ALS in general, will require intensive international cooperation to obtain large sample sizes of patients with ALS with a specific genotype. For instance, the prevalence of the UNC13A C/C genotype is $12.2 \%-19.5 \%{ }^{9,12,15}$ among patients with ALS. This would result in a screening failure rate of $80.5 \%-87.8 \%$ on genotype alone. Large numbers of patients will need to be approached to ensure an acceptable phase III clinical trial sample size. For instance, 140 UNC13A carriers would be required to detect a HR of 0.62 by a 2 -sided log-rank test with 90\% power, assuming a 1-year survival of $50 \%$ in the placebo group, indicating that in the worst case (UNC13A prevalence of $12.2 \%$ ), approximately 1,100 patients need to be genotyped.

ALS is both clinically and genetically a highly heterogeneous disease and it is this complexity that seems to complicate the development of effective treatment for our patients. Even in carefully selected trial populations, the genotype significantly affected the primary outcome measure-survival-in ALS trials. The assumption of a homogenous treatment effect across patients with ALS, for lithium specifically and ALS trials in general, seems no longer tenable and genetic subgroups of patients may modify the treatment effect. The results from this study suggest that we should reorient our strategies toward finding treatments for ALS and start focusing on genotypetargeted treatments and standardize genotyping in order to optimize randomization and analysis in ALS clinical trials.

\section{AUTHOR CONTRIBUTIONS}

M.A.v.E. was responsible for the study concept. The chief investigators of randomized trials of lithium carbonate in patients with ALS were A.A.-C. (LiCALS), A.C. (LITALS), and L.H.v.d.B. (LITRA). R.P.A.v.E., M.A.v. E., and A.A.-C. wrote the protocol. A.R.J., A.S., P.J.S., P.N.L., C.A.Y., C.E.S., G.M., J.M., G.B., P.V., F.P.D., W.v.R., and E.V. contributed substantially to data acquisition and interpretation of the analysis. R.P. A.v.E., M.A.v.E., and M.J.C.E. analyzed the data. M.A.v.E. and R.P. A.v.E. drafted the final manuscript, which was reviewed, edited, and approved by all the authors.

\section{STUDY FUNDING}

Funding was received from the Netherlands ALS Foundation (Project TryMe) and UK Motor Neurone Disease Association (MNDA). This project was supported by the following funding organizations under the aegis of JPND—www.jpnd.eu (United Kingdom, Medical Research Council, MR/L501529/1); Netherlands, ZonMW; and Italy, MIUR.

\section{DISCLOSURE}

R. van Eijk, A. Jones, W. Sproviero, and A. Shatunov report no disclosures relevant to the manuscript. P. Shaw is supported by the MND Association as an NIHR Senior Investigator. P. Leigh reports no disclosures relevant to the manuscript. C. Young reports grants from MS Society, UK Motor Neurone Disease Association (MNDA), Bayer, Biogen, Genzyme, Merck, Novartis, Roche, and Teva, and serves on the health research advisory panel of the MNDA. She has had travel grants or speaker/consultancy fees from Genzyme, Merck, Novartis, Roche, Teva, and Wellcome Trust. C. Shaw is supported by the UK Dementia Research Institute, which is funded by the Medical Research Council, Alzheimer's Society, and Alzheimer's Research UK. G. Mora, J. Mandrioli, G. Borghero, P. Volanti, F. Diekstra, W. van Rheenen, E. Verstraete, M. Eijkemans, J. Veldink, A. Chio, and A. Al-Chalabi report no disclosures relevant to the manuscript. L. van den Berg reports grants from Netherlands ALS Foundation, the Netherlands Organization for Health Research and Development (Vici scheme), and the Netherlands Organization for Health Research and Development (SOPHIA, STRENGTH, ALS-CarE project), funded through the EU Joint Programme-Neurodegenerative Disease Research, JPND); and served on the Scientific Advisory Board of Biogen, Cytokinetics, Prinses Beatrix SpierFonds, and the Latran Foundation. M. van Es received grants from the Netherlands Organization for Health Research and Development (Veni scheme), The Thierry Latran foundation and the Netherlands ALS foundation (Stichting ALS Nederland). He received travel grants from Baxalta and serves on the biomedical research advisory panel of the MNDA. AAC receives salary support from the National Institute for Health Research (NIHR) Biomedical Research Centre at South London and Maudsley NHS Foundation Trust and King's College London; reports grants from the ALS Association, MND Association, EU H2020 scheme, MRC, and NIHR; and serves on the scientific advisory board of the ALS Association, Cytokinetics Inc., Biogen Idec, and OrionPharma. Go to Neurology.org for full disclosures.

Received May 19, 2017. Accepted in final form August 18, 2017.

\section{REFERENCES}

1. Bensimon G, Lacomblez L, Meininger V. A controlled trial of riluzole in amyotrophic lateral sclerosis: ALS/Riluzole Study Group. N Engl J Med 1994;330:585-591.

2. Mitsumoto $\mathrm{H}$, Brooks BR, Silani V. Clinical trials in amyotrophic lateral sclerosis: why so many negative trials and how can trials be improved? Lancet Neurol 2014;13: 1127-1138.

3. Su XW, Broach JR, Connor JR, Gerhard GS, Simmons Z. Genetic heterogeneity of amyotrophic lateral sclerosis: implications for clinical practice and research. Muscle Nerve 2014;49:786-803. 
4. Chapman PB, Hauschild A, Robert C, et al; BRIM-3 Study Group. Improved survival with vemurafenib in melanoma with BRAF V600E mutation. N Engl J Med 2011; 364:2507-2516.

5. Miller TM, Pestronk A, David W, et al. An antisense oligonucleotide against SOD1 delivered intrathecally for patients with SOD1 familial amyotrophic lateral sclerosis: a phase 1 , randomised, first-in-man study. Lancet Neurol 2013;12:435-442.

6. Lange DJ, Andersen PM, Remanan R, Marklund S, Benjamin D. Pyrimethamine decreases levels of SOD1 in leukocytes and cerebrospinal fluid of ALS patients: a phase I pilot study. Amyotroph Lateral Scler Frontotemporal Degener 2013;14:199-204.

7. Majounie E, Renton AE, Mok K, et al. Frequency of the C9orf72 hexanucleotide repeat expansion in patients with amyotrophic lateral sclerosis and frontotemporal dementia: a cross-sectional study. Lancet Neurol 2012;11:323-330.

8. van Rheenen W, van Blitterswijk M, Huisman MH, et al. Hexanucleotide repeat expansions in C9ORF72 in the spectrum of motor neuron diseases. Neurology 2012;79: 878-882.

9. van Es MA, Veldink JH, Saris CG, et al. Genome-wide association study identifies 19p13.3 (UNC13A) and 9p21. 2 as susceptibility loci for sporadic amyotrophic lateral sclerosis. Nat Genet 2009;41:1083-1087.

10. Daoud H, Belzil V, Desjarlais A, Camu W, Dion PA, Rouleau GA. Analysis of the UNC13A gene as a risk factor for sporadic amyotrophic lateral sclerosis. Arch Neurol 2010;67:516-517.

11. Diekstra FP, Van Deerlin VM, van Swieten JC, et al. C9orf72 and UNC13A are shared risk loci for amyotrophic lateral sclerosis and frontotemporal dementia: a genomewide meta-analysis. Ann Neurol 2014;76:120-133.

12. Chio A, Mora G, Restagno G, et al. UNC13A influences survival in Italian amyotrophic lateral sclerosis patients: a population-based study. Neurobiol Aging 2013;34: 357.e351-357.e355.

13. Gaastra B, Shatunov A, Pulit S, et al. Rare genetic variation in UNC13A may modify survival in amyotrophic lateral sclerosis. Amyotroph Lateral Scler Frontotemporal Degener 2016;17:593-599.

14. Diekstra FP, van Vught PW, van Rheenen W, et al UNC13A is a modifier of survival in amyotrophic latera sclerosis. Neurobiol Aging 2012;33:630.e633-630.e638.

15. Vidal-Taboada JM, Lopez-Lopez A, Salvado M, et al. UNC13A confers risk for sporadic ALS and influences survival in a Spanish cohort. J Neurol 2015;262:2285-2292.

16. Higgins JPT, Green S; Cochrane Collaboration. Cochrane Handbook for Systematic Reviews of Interventions. Chichester, UK: Wiley-Blackwell; 2008.

17. Akimoto C, Volk AE, van Blitterswijk M, et al. A blinded international study on the reliability of genetic testing for GGGGCC-repeat expansions in C9orf72 reveals marked differences in results among 14 laboratories. J Med Genet 2014;51:419-424.

18. van Es MA, van Vught PW, Veldink JH, et al. Analysis of FGGY as a risk factor for sporadic amyotrophic lateral sclerosis. Amyotroph Lateral Scler 2009;10:441-447.

19. Cooper-Knock J, Hewitt C, Highley JR, et al. Clinicopathological features in amyotrophic lateral sclerosis with expansions in C9ORF72. Brain 2012;135:751-764.
20. Abo-Zaid G, Guo B, Deeks JJ, et al. Individual participant data meta-analyses should not ignore clustering. J Clin Epidemiol 2013;66:865-873.e864.

21. White IR, Thompson SG. Adjusting for partially missing baseline measurements in randomized trials. Stat Med 2005;24:993-1007.

22. Chio A, Borghero G, Calvo A, et al; LITALS Study Group. Lithium carbonate in amyotrophic lateral sclerosis: lack of efficacy in a dose-finding trial. Neurology 2010;75: 619-625.

23. Kahan BC, Jairath V, Dore CJ, Morris TP. The risks and rewards of covariate adjustment in randomized trials: an assessment of 12 outcomes from 8 studies. Trials 2014;15: 139.

24. Aggarwal SP, Zinman L, Simpson E, et al; Northeast and Canadian Amyotrophic Lateral Sclerosis consortia. Safety and efficacy of lithium in combination with riluzole for treatment of amyotrophic lateral sclerosis: a randomised, double-blind, placebo-controlled trial. Lancet Neurol 2010;9:481-488.

25. Kernan WN, Viscoli CM, Makuch RW, Brass LM, Horwitz RI. Stratified randomization for clinical trials. J Clin Epidemiol 1999;52:19-26.

26. Fornai F, Longone P, Cafaro L, et al. Lithium delays progression of amyotrophic lateral sclerosis. Proc Natl Acad Sci USA 2008;105:2052-2057.

27. Lacomblez L, Bensimon G, Leigh PN, Guillet P, Meininger V. Dose-ranging study of riluzole in amyotrophic lateral sclerosis: Amyotrophic Lateral Sclerosis/Riluzole Study Group II. Lancet 1996;347:1425-1431.

28. Broeke JH, Roelandse M, Luteijn MJ, et al. Munc18 and Munc13 regulate early neurite outgrowth. Biol Cell 2010; 102:479-488.

29. Forlenza OV, De-Paula VJR, Diniz BSO. Neuroprotective effects of lithium: implications for the treatment of Alzheimer's disease and related neurodegenerative disorders. ACS Chem Neurosci 2014;5:443-450.

30. Ramasamy A, Trabzuni D, Guelfi S, et al. Genetic variability in the regulation of gene expression in ten regions of the human brain. Nat Neurosci 2014;17: 1418-1428.

31. van Rheenen W, Shatunov A, Dekker AM, et al. Genomewide association analyses identify new risk variants and the genetic architecture of amyotrophic lateral sclerosis. Nat Genet 2016;48:1043-1048.

32. Wang R, Lagakos SW, Ware JH, Hunter DJ, Drazen JM. Statistics in medicine-reporting of subgroup analyses in clinical trials. N Engl J Med 2007;357:2189-2194.

33. Brooks BR, Miller RG, Swash M, Munsat TL; World Federation of Neurology Research Group on Motor Neuron D. El Escorial revisited: revised criteria for the diagnosis of amyotrophic lateral sclerosis. Amyotroph Lateral Scler Other Motor Neuron Disord 2000;1:293-299.

34. Verstraete E, Veldink JH, Huisman MH, et al. Lithium lacks effect on survival in amyotrophic lateral sclerosis: a phase IIb randomised sequential trial. J Neurol Neurosurg Psychiatry 2012;83:557-564.

35. UKMND-LiCALS Study Group, Al-Chalabi A, Allen C, et al. Lithium in patients with amyotrophic lateral sclerosis (LiCALS): a phase 3 multicentre, randomised, doubleblind, placebo-controlled trial. Lancet Neurol 2013;12: 339-345. 


\section{Neurology}

\section{Meta-analysis of pharmacogenetic interactions in amyotrophic lateral sclerosis clinical}

trials

Ruben P.A. van Eijk, Ashley R. Jones, William Sproviero, et al.

Neurology 2017;89;1915-1922 Published Online before print October 4, 2017

DOI 10.1212/WNL.0000000000004606

This information is current as of October 4, 2017

Neurology ${ }^{\circledR}$ is the official journal of the American Academy of Neurology. Published continuously since 1951, it is now a weekly with 48 issues per year. Copyright Copyright $@ 2017$ The Author(s). Published by Wolters Kluwer Health, Inc. on behalf of the American Academy of Neurology.. All rights reserved. Print ISSN: 0028-3878. Online ISSN: 1526-632X.

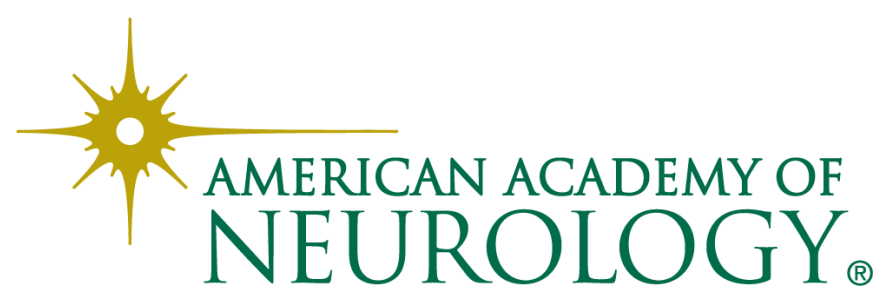




\section{Updated Information \& Services}

\section{Supplementary Material}

\section{References}

\section{Citations}

Subspecialty Collections

\section{Errata}

\section{Permissions \& Licensing}

\section{Reprints}

including high resolution figures, can be found at: http://n.neurology.org/content/89/18/1915.full

Supplementary material can be found at: http://n.neurology.org/content/suppl/2017/10/04/WNL.0000000000004 606.DC1

http://n.neurology.org/content/suppl/2017/10/04/WNL.0000000000004 606.DC2

http://n.neurology.org/content/suppl/2017/10/04/WNL.0000000000004 606.DC3

This article cites 34 articles, 5 of which you can access for free at: http://n.neurology.org/content/89/18/1915.full\#ref-list-1

This article has been cited by 5 HighWire-hosted articles: http://n.neurology.org/content/89/18/1915.full\#\#otherarticles

This article, along with others on similar topics, appears in the following collection(s):

\section{All Genetics}

http://n.neurology.org/cgi/collection/all_genetics

Amyotrophic lateral sclerosis

http://n.neurology.org/cgi/collection/amyotrophic_lateral_sclerosis_ Clinical trials Systematic review/meta analysis

http://n.neurology.org/cgi/collection/clinical_trials_systematic_review_ meta_analysis_

An erratum has been published regarding this article. Please see next page or:

/content/89/22/2303.full.pdf

Information about reproducing this article in parts (figures,tables) or in its entirety can be found online at:

http://www.neurology.org/about/about_the_journal\#permissions

Information about ordering reprints can be found online:

http://n.neurology.org/subscribers/advertise

Neurology ${ }^{\circledR}$ is the official journal of the American Academy of Neurology. Published continuously since 1951, it is now a weekly with 48 issues per year. Copyright Copyright ( 2017 The Author(s). Published by Wolters Kluwer Health, Inc. on behalf of the American Academy of Neurology.. All rights reserved. Print ISSN: 0028-3878. Online ISSN: 1526-632X.

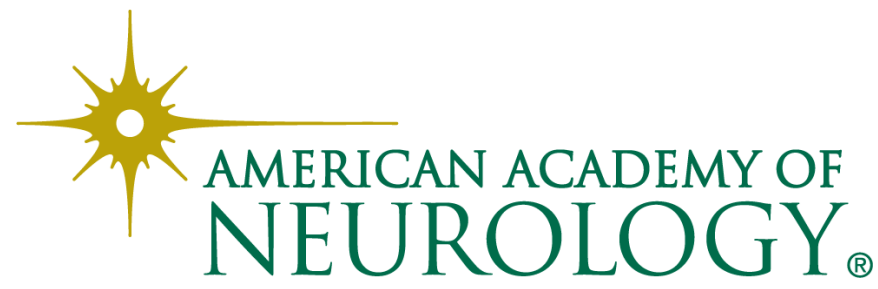


Editors' Note: In "Practice guideline summary: Reducing brain injury following cardiopulmonary resuscitation: Report of the Guideline Development, Dissemination, and Implementation Subcommittee of the American Academy of Neurology," the authors concluded that prehospital cooling did not improve neurologic outcome or survival in patients who subsequently underwent in-hospital therapeutic hypothermia. Drs. Machado et al. comment that studies in animals and of accidental hypothermia have shown a benefit to early hypothermia, and that, intuitively, any neuroprotective intervention should be initiated as soon as possible. Authors Geocadin et al. confirm that while animal studies and case reports in support of prehospital cooling exist, multiple human studies failed to demonstrate any benefit. Regarding these same guidelines, Drs. Melegari et al. describe their observation of 32 patients treated with therapeutic hypothermia after an out-of-hospital cardiac arrest over 2 years. They found that patients after a cardiac arrest in which there was a nonshockable rhythm and circulatory instability fared worse due to subsequent cerebral edema. Patients without these factors benefited from the mild therapeutic hypothermia. Authors Geocadin et al. comment that the relationship between these factors (i.e., rhythm during cardiopulmonary resuscitation [CPR] and cerebral edema) and post-CPR management is not clear in the literature and that more research is needed to answer these important questions. -Megan Alcauskas, MD, and Steven Galetta, MD

\footnotetext{
LETTER RE: PRACTICE GUIDELINE SUMMARY: REDUCING BRAIN INJURY FOLLOWING CARDIOPULMONARY RESUSCITATION: REPORT OF THE GUIDELINE DEVELOPMENT, DISSEMINATION, AND IMPLEMENTATION SUBCOMMITTEE OF THE AMERICAN ACADEMY OF NEUROLOGY

Calixto Machado, Mario Estevez, Habana, Cuba; Gerry Leisman, Zichron Ya'acov, Israel: The American Academy of Neurology guidelines remarked on required recommendations to reduce brain injury after successful cardiopulmonary resuscitation (CPR). ${ }^{1}$ Nonetheless, it seems contradictory that prehospital cooling as an adjunct to therapeutic hypothermia (TH) is decidedly ineffectual in further improving neurologic outcome and survival.
}

Safar and Tisherman ${ }^{2}$ documented brain and organ preservation during cardio-circulatory arrest (CCA) in dog experimental models with no-flow durations of up to 90 or 120 minutes. The neuroprotective effect of TH is also supported by reports of patients with accidental hypothermia, combined with CCA. These patients were rewarmed by use of extracorporeal circulation with good outcome in several cases. ${ }^{3}$ The key point in these cases was that the neuroprotective effect of accidental hypothermia occurred very early, even before a complete CCA had occurred. ${ }^{4}$

Out-of-hospital settings (i.e., the site of accident or inside ambulances) include technical limitations in patients with an absent or unstable blood circulation and possible neurologic complications. ${ }^{1,4,5}$ Any neuroprotective treatment for preventing brain injury after CCA should be initiated as soon as possible and maintained during $\mathrm{CPR}$. ${ }^{4}$

1. Geocadin RG, Wijdicks E, Armstrong MJ, et al. Practice guideline summary: Reducing brain injury following cardiopulmonary resuscitation: report of the Guideline Development, Dissemination, and Implementation Subcommittee of the American Academy of Neurology. Neurology 2017;88:2141-2149.

2. Safar PJ, Tisherman SA. Suspended animation for delayed resuscitation. Curr Opin Anaesthesiol 2002;15:203-210.

3. Oberhammer R, Beikircher W, Hormann C, et al. Full recovery of an avalanche victim with profound hypothermia and prolonged cardiac arrest treated by extracorporeal rewarming. Resuscitation 2008;76:474-480.

4. Machado C. The brain is the target organ in cardiorespiratory reanimation. Curr Anaesth Crit Care 2009;20:148.

5. Zafren K. Out-of-hospital evaluation and treatment of accidental hypothermia. Emerg Med Clin North Am 2017;35: 261-279.

(C) 2017 American Academy of Neurology

LETTER RE: PRACTICE GUIDELINE SUMMARY: REDUCING BRAIN INJURY FOLLOWING CARDIOPULMONARY RESUSCITATION: REPORT OF THE GUIDELINE DEVELOPMENT, DISSEMINATION, AND IMPLEMENTATION SUBCOMMITTEE OF THE AMERICAN ACADEMY OF NEUROLOGY

Gabriele Melegari, Alberto Barbieri, Antonio Manenti, Elisabetta Bertellini, Enrico Giuliani, Modena, Italy: We read with interest the article by Geocadin et al. ${ }^{1}$ and found the conclusion of 
importance. Over the last 2 years, we observed a group of 32 patients treated with mild therapeutic hypothermia after an out-of-hospital nontraumatic cardiac arrest. When considering the effect of the cardiac arrest on the patients' subsequent outcomes in the short and middle term, a sharp difference between 2 conditions was observed. A cardiac arrest complicated by a not-shockable rhythm and a circulatory instability is usually accompanied by a worsening cerebral edema. These 2 signs, clearly connected to each other, are strong predictors of short survival and of poor neurologic outcome, independent from any treatment. On the contrary, in the case of cardiac arrest followed by a shockable rhythm, mild therapeutic hypothermia is directly indicated for the greater possibility of a good outcome. $^{2-4}$ In these patients, any early invasive treatment of the acute cardiac pathology, or of any other intervening complication, is not contraindicated.

1. Geocadin RG, Wijdicks E, Armstrong MJ, et al. Practice guideline summary: Reducing brain injury following cardiopulmonary resuscitation: report of the Guideline Development, Dissemination, and Implementation Subcommittee of the American Academy of Neurology. Neurology 2017; 88:2141-2149.

2. Zheng R, Luo S, Liao J, et al. Conversion to shockable rhythms is associated with better outcomes in out-ofhospital cardiac arrest patients with initial asystole but not in those with pulseless electrical activity. Resuscitation 2016;107:88-93.

3. Wah W, Wai KL, Pek PP, et al. Conversion to shockable rhythms during resuscitation and survival for out-ofhospital cardiac arrest. Am J Emerg Med 2017;35: 206-213.

4. Granau B, Reynolds JC, Sheuermeyer FX, et al. Comparing the prognosis of those with initial shockable and nonshockable rhythms with increasing durations of CPR: informing minimum durations of resuscitation. Resuscitation 2016;101:50-56.

C 2017 American Academy of Neurology

AUTHOR RESPONSE: PRACTICE GUIDELINE
SUMMARY: REDUCING BRAIN INJURY
FOLLOWING CARDIOPULMONARY
RESUSCITATION: REPORT OF THE GUIDELINE
DEVELOPMENT, DISSEMINATION, AND
IMPLEMENTATION SUBCOMMITTEE OF THE
AMERICAN ACADEMY OF NEUROLOGY

Romergryko G. Geocadin, Baltimore; Eelco Wijdicks, Rochester, MN; Richard M. Dubinsky, Kansas City, KS; Joseph P. Ornato, Richmond, VA; Michael T. Torbey, Columbus, OH; Jose I. Suarez, Houston: We appreciate the comments of Machado et al. and Melegari et al. on our guideline, which provided recommendations to reduce brain injury following cardiopulmonary resuscitation (CPR). ${ }^{1}$

Despite the promising results in animal studies (many used hypothermia during resuscitation or minutes thereafter in controlled circumstances) with the early initiation of therapeutic hypothermia $(\mathrm{TH})$, as mentioned by Machado et al., multiple human studies (5 Class I and 1 Class II) failed to demonstrate any benefit of prehospital TH followed by $\mathrm{TH}$ in-hospital vs only $\mathrm{TH}$ in-hospital for comatose survivors of out-of-hospital cardiac arrest (OHCA). ${ }^{2-7}$ Many factors may have contributed to the difference in outcomes between animal studies and human trials, including the difference in time of initiation, methods, and application consistency of $\mathrm{TH}$ in relation to CPR. While case reports exist of good survival of people who had extreme accidental hypothermia followed by cardiac arrest, the pathophysiologic mechanism is quite different from the controlled clinical trials of TH after OHCA included in the practice guideline. ${ }^{1}$

The comments of Melegari et al. are based on their observation of 32 patients post CPR who were treated with mild TH. A population-based cardiac arrest study showed the associations of nonshockable cardiac rhythm to preexisting noncardiovascular diseases and shockable cardiac rhythms to preexisting cardiovascular diseases. ${ }^{8}$ Although some association has been attributed to preexisting conditions (e.g., cardiac disease and lung disease) and measures during CPR (e.g., cardiac rhythm and arrest time) to the outcomes after successful CPR, these conditions were found less reliable as predictors of neurologic outcome. ${ }^{9-11}$ Some post-CPR measures, such as neurologic examination and somatosensory evoked potentials, are deemed reliable as predictors of neurologic outcome ${ }^{9-11}$; however, neuroimaging (e.g., CT scan and MRI) after CPR to detect extent of brain injury (e.g., brain edema) is not considered reliable as a predictor of outcome. ${ }^{9,11,12}$ After a careful literature review, the effects of factors (i.e., cardiac rhythm during CPR and cerebral edema) provided by Melegari et al. to post-CPR management remain unclear. Furthermore, no studies have shown the precise link of cardiac arrest and brain edema. More research is needed. Until better data are available, the recommendations remain as provided in the guideline. ${ }^{1}$

1. Geocadin RG, Wijdicks E, Armstrong MJ, et al. Practice guideline summary: Reducing brain injury following cardiopulmonary resuscitation: report of the Guideline Development, Dissemination, and Implementation Subcommittee of the American Academy of Neurology. Neurology 2017;88:2141-2149.

2. Kim F, Nichol G, Maynard C, et al. Effect of prehospital induction of mild hypothermia on survival and neurological status among adults with cardiac arrest: a randomized clinical trial. JAMA 2014;311:45-52.

3. Castren M, Nordberg P, Svensson L, et al. Intra-arrest transnasal evaporative cooling: a randomized, prehospital, multicenter study (PRINCE: Pre-ROSC IntraNasal Cooling Effectiveness). Circulation 2010;122:729-736. 
4. Bernard SA, Smith K, Cameron P, et al. Induction of therapeutic hypothermia by paramedics after resuscitation from out-of-hospital ventricular fibrillation cardiac arrest: a randomized controlled trial. Circulation 2010;122:737742.

5. Bernard SA, Smith K, Cameron P, et al. Induction of prehospital therapeutic hypothermia after resuscitation from nonventricular fibrillation cardiac arrest. Crit Care Med 2012;40:747-753.

6. Kamarainen A, Virkkunen I, Tenhunen J, Yli-Hankala A, Silfvast T. Prehospital therapeutic hypothermia for comatose survivors of cardiac arrest: a randomized controlled trial. Acta Anaesthesiol Scand 2009;53:900-907.

7. Debaty G, Maignan M, Savary D, et al. Impact of intraarrest therapeutic hypothermia in outcomes of prehospital cardiac arrest: a randomized controlled trial. Intensive Care Med 2014;40:1832-1842.

8. Granfeldt A, Wissenberg M, Hansen SM, et al. Clinical predictors of shockable versus non-shockable rhythms in patients with out-of-hospital cardiac arrest. Resuscitation 2016;108:40-47.

9. Wijdicks EF, Hijdra A, Young GB, et al. Practice parameter: Prediction of outcome in comatose survivors after cardiopulmonary resuscitation (an evidence-based review): report of the Quality Standards Subcommittee of the American Academy of Neurology. Neurology 2006;67:203-210.
10. Neumar RW, Nolan JP, Adrie C, et al. Post-cardiac arrest syndrome: epidemiology, pathophysiology, treatment, and prognostication: a consensus statement from the International Liaison Committee on Resuscitation (American Heart Association, Australian and New Zealand Council on Resuscitation, European Resuscitation Council, Heart and Stroke Foundation of Canada, InterAmerican Heart Foundation, Resuscitation Council of Asia, and the Resuscitation Council of Southern Africa); the American Heart Association Emergency Cardiovascular Care Committee; the Council on Cardiovascular Surgery and Anesthesia; the Council on Cardiopulmonary, Perioperative, and Critical Care; the Council on Clinical Cardiology; and the Stroke Council. Circulation 2008;118:2452-2483.

11. Callaway CW, Donnino MW, Fink EL, et al. Part 8: Postcardiac arrest care: 2015 American Heart Association Guidelines Update for Cardiopulmonary Resuscitation and Emergency Cardiovascular Care. Circulation 2015; 132:S465-S482.

12. Hahn DK, Geocadin RG, Greer DM. Quality of evidence in studies evaluating neuroimaging for neurologic prognostication in adult patients resuscitated from cardiac arrest. Resuscitation 2014;85:165-172.

(C) 2017 American Academy of Neurology

\section{CORRECTION}

\section{Meta-analysis of pharmacogenetic interactions in amyotrophic lateral sclerosis clinical trials}

In the article "Meta-analysis of pharmacogenetic interactions in amyotrophic lateral sclerosis clinical trials" by R.P.A. van Eijk et al., ${ }^{1}$ there was an error in figure 2 of the version published online on October 4, 2017. The key in figure 2 should have labeled the green line "UNC13A carriers - Lithium" and the purple line "UNC13A carriers - Control." In subsequent versions of the article (republished online on October 11, 2017, and in the issue dated October 31, 2017), figure 2 is correct. The editorial staff regret the error in the first version.

\section{REFERENCE}

1. van Eijk RPA, Jones AR, Sproviero W, et al. Meta-analysis of pharmacogenetic interactions in amyotrophic lateral sclerosis clinical trials. Neurology 2017;89:1915-1922. 